\title{
FAKTOR-FAKTOR PENENTU PENINGKATAN KINERJA PENYULUH PERTANIAN DALAM MEMBERDAYAKAN PETANI (Kasus di Kabupaten Kampar Provinsi Riau)
}

\section{DETERMINANT FACTORS TO INCREASE AGRI-EXTENSIONWORKER PERFORMANCE TO EMPOWER FARMER (A CASE STUDY IN DISTRICT OF KAMPAR, RIAU PROVINCE)}

\author{
Marliati, Sumardjo, Pang S. Asngari, \\ Prabowo Tjitropranoto dan Asep Saefuddin
}

\begin{abstract}
The agriculture extension program can be developed effectively and efficiently by professional personal in agriculture extension field. The existing main problem is low quality and quantity of agri-extension workers (include in Kampar district, Riau province). Therefore, the goals of this research are: (1) To analyze: farmer characteristics; social system characteistics; agri-extension worker competencies; agri-extension worker performance to empower farmer and level of fulfill need for farmer's capacity development in agribusiness; (2) To analyze determinant factors which influenze agri-extension worker performance to empowering farmer and (3) To formulate strategy to increase agri-extension worker performance to empower farmer. Through multistage cluster sampling technique, this research have found farmers sample with 180 person amoun (each of them consist of: 60 food crops farmers, 60 oil palm farmers and 60 rubber farmers). This research have been done from June 2007 up to October 2007. The analysis of data done by descriptive analysis and Path analysis. The research conclusion are: performance level of agri-extension worker to empower farmer still not yet good ("enough" category) because of the influence factor to the performance of agri-extension worker: agri-extension worker competencies (communication competency; competency in farmers learning and competency in social interaction); farmer characteristics ( farmer's access to the non formal education) and social sistem support (soscio-cultural values; agribusiness facilitation by government institution and fartmer's access to the aggribusiness institution) are still not yet ("enough" category).
\end{abstract}

Keys word: agri- extension worker performance; empowerment

\section{Pendahuluan}

Menurut Slamet (2003), program penyuluhan pembangunan yang efektif dan efisien dapat dikembangkan oleh tenagatenaga profesional di bidang penyuluhan pembangunan Hal ini hanya memungkinkan apabila program penyuluhan diwadahi oleh sistem kelembagaan penyuluhan yang jelas dan pelaksanaanya didukung oleh tenaga- tenaga yang kompeten di bidang penyuluhan. Peningkatan kompetensi penyuluh dalam pembangunan pertanian, bisa dikondisikan melalui berbagai upaya seperti: (1) meningkatkan efektivitas pelatihan bagi penyuluh, (2) meningkatkan pengembangan diri penyuluh melalui peningkatan kemandirian belajar dan pengembangan karir penyuluh, (3) meningkatkan dukungan terhadap penyelenggaraan penyuluhan seperti 
dukungan kebijakan pemerintah daerah terhadap pendanaan penyuluhan, dukungan peran kelembagaan, dukungan teknologi dan sarana penyuluhan, pola kepemimpinan yang berpihak petani dan (4) memotivas pribadi penyuluh untuik selalu meningkatkan prestasi kerja (kinerja penyuluh) dan mengikuti perubahan lingkungan strategis yang ada.

Sejalan dengan pemikiran Slamet (2003) tersebut, pemerintah telah melakukan berbagai upaya, di antaranya telah dicanangkannya Revitalisasi Penyuluhan Pertanian (RPP), yaitu suatu upaya mendudukkan, memerankan dan memfungsikan serta menata kembali penyuluhan pertanian agar terwujud kesatuan pengertian, kesatuan korp dan kesatuan arah kebijakan. Salah satu tonggak untuk pelaksanaan revitalisasi ini adalah telah disyahkannya Undang-undang Sistem Penyuluhan Pertanian, Perikanan dan Kehutanan (SP3K) No. 16 Tahun 2006 pada tanggal 18 Oktober 2006. UU ini merupakan suatu titik awal dalam pemberdayaan para petani melalui peningkatan sumberdaya manusia dan kelembagaan para penyuluh pertanian PNS, swasta dan penyuluh pertanian swadaya.

Permasalahan pokok yang dihadapi selama ini adalah rendahnya kualitas dan kuantitas tenaga penyuluh (termasuk di kabupaten Kampar provinsi Riau). Penelitian ini dimaksudkan untuk menganalisis faktorfaktor penentu manakah yang efektif berpengaruh terhadap tingkat kinerja penyuluh pertanian. Diharapkan dari hasil penelitian ini mampu memberikan sumbang pemikiran bagi peningkatan kualitas kinerja penyuluh pertanian yang mampu meningkatkan kapasitas dan kemandirian petani.

Kinerja yang dimaksudkan dalam penelitian ini adalah mengacu kepada pendapat Gruneberg (1979), yaitu perilaku yang diperagakan secara aktual oleh seseorang sebagai respon terhadap tugas yang diembannya. Tujuan penyuluhan pertanian adalah untuk meningkatkan kapasitas (keberdayaan) dan kemandirian petani, maka kinerja penyuluhan adalah kinerja yang mengacu kepada konsep-konsep pemberdayaan yaitu yang mampu meningkatkan kapasitas (keberdayaan) dan kemandirian petani. Berdasarkan kajian deduktif yang mengacu kepada pemikiran Sayogyo (1999), Florus (1998), Ife (1995), Slamet (2003), Narayan (2002) dan Sumardjo dkk. (2002), minimal ada enam tugas pokok penyuluh pertanian yang bertujuan untuk pemenuhan pengembangan kapasitas dan kemandirian petani, yaitu: (1) Pengembangan perilaku keinovatifan petani; (2) Penguatan partisipasi petani; (3) Penguatan kelembagaan petani; (4) Pengutan akses petani terhadap berbagai sumberdaya; (5) Penguatan kemampuan petani berjaringan dan (6) Kaderisasi.

Kinerja penyuluh pertanian dipengaruhi oleh faktor internal dan eksternal penyuluh. Kinerja penyuluh dalam penelitian ini adalah dipersepsikan oleh tingkat kepuasan petani yang menerima jasa penyuluhan pertanian. Faktor internal yang diduga berpengaruh terhadap kinerja penyuluh adalah kompetensi penyuluh pertanian. Faktor eksternal yang diduga berpengaruh terhadap kinerja penyuluh adalah karakteristik sistem sosial (yaitu aspek-aspek yang mendukungan/menghambat perubahan dalam sistem sosial sebagai akibat proses intervensi pembangunan pertanian).

Berdasarkan latar belakang pemikiran tersebut, permasalahan utama penelitian ini adalah: (1) Sejauhmana karakteristik petani, karakteristik sistem sosial, tingkat kompetensi penyuluh pertanian dan tingkat kinerja penyuluh pertanian dan (2) Faktor-faktor penentu manakah yang berpengaruh efektif terhadap tingkat kinerja penyuluh pertanian dalam memberdaykan petani. Berdasarkan permasalahan utama, tujuan penelitian ini adalah: (1) Menganalisis karakteristik petani, karakteristik sistem sosial, tingkat kompetensi penyuluh pertanian dan tingkat kinerja penyuluh pertanian dalam memberdayakan petani; (2) Meng-analisis faktor-faktor yang berpengaruh terhadap kinerja penyuluh pertanian dan (3) Merumuskan strategi 
peningkatan kinerja penyuluh pertanian dalam memberdayakan petani.

\section{$\underline{\text { Metode Penelitian }}$}

Penelitian ini adalah penelitian penjelasan (explanatory research), yaitu menjelaskan hubungan kausalitas antara peubah-peubah melalui pengujian hipotesis. Model teoritis yang akan diuji dalam penelitian ini meliputi beberapa bentuk hubungan antar peubah, yaitu hubungan peubah bebas karakteristik petani $\mathrm{X}_{1}$ (umur; pendidikan formal; pendidikan non formal dan pengalaman petani berusahatani), karakteristik sistem sosial $\mathrm{X}_{2}$ (nilai-nilai sosial budaya; sistem kelembagaan petani; dukungan tenaga ahli dan kelembagaan penelitian dan penyuluhan; fasilitasi oleh lembaga pemerintah terkait; dukungan kelembagaan agribisnis dan kepemimpinan lokal) dan kompetensi penyuluh pertanian $\mathrm{X}_{3}$ (kompetensi managerial, kompetensi komunikasi, kompetensi mengorganisasikan kegiatan belajar petani dan kompetensi interaksi sosial) dengan peubah terikat yaitu kinerja penyuluh pertanian $\mathrm{Y}_{1}$. Peubah dan sub peubah dalam penelitian ini diukur berdasarkan persepsi petani.

Penelitian dilakukan di Kabupaten Kampar Provinsi Riau. Kabupaten Kampar merupakan salah satu kabupaten memiliki potensi pengembangan agribisnis di provinsi Riau. Penelitian dilakukan dari bulan Juni 2007 sampai dengan Oktober 2007. Pengambilan sampel petani (responden penelitian) dilakukan dengan metode pengambilan sampel gugus bertahap (multistage cluster sampling). Melalui metode pengambilan sampel ini, terpilih jumlah responden penelitian 180 orang petani (yang terdiri masing-masing 60 orang petani tanaman pangan, kelapa sawit dan karet).

Data yang digunakan dalam penelitian, meliputi data primer dan data sekunder. Data primer diperoleh dengan menggunakan kuesioner terstruktur, wawancara mendalam, Diskusi Kelompok Terarah (Focus Group
Discussion) dan pengamatan partisipasi (participant observation). Data sekunder diperoleh melalui studi dokumentasi dan studi literatur.

\section{Hasil dan Pembahasan}

\section{$\underline{\text { Karakteristik Petani }}$}

Petani berada pada usia produktif (rataan 41 tahun) dan belum didukung oleh tingkat pendidikan formal dan pendidikan non formal yang memadai. Rataan pendidikan formal 9 tahun (setingkat tamat SLTP) dan rataan mengikuti pendidikan non formal 7 hari. Dilihat dari modus, petani dominan (yaitu 48,2 persen) belum pernah mengikuti pendidikan non formal (kursus atau pelatihan). Pengalaman petani beragribisnis yaitu rataan 13,69 tahun diharapkan menunjang keberhasilan agribisnis petani, namun belum didukung oleh luas penguasaan lahan pertanian yang memadai, rataan hanya 1,61 hektar (karena 66,.67 persen petani memiliki kebun sawit dan karet).

\section{$\underline{\text { Karakteristik Sistem Sosial }}$}

Karakteritik sistem sosial adalah faktor-faktor yang menghambat/mendukung perubahan sistem sosial sebagai akibat intervensi pembangunan pertanian.. Semua aspek-aspek (6 aspek) karakteristik sistem sosial (Tabel 2) termasuk kategori "cukup." Artinya, semua aspek-aspek dari sistem sosial yaitu: nilai-nilai sosial budaya (antara lain tingkat keinovatifan petani dan tingkat kegotong royongan); sistem kelembagaan (tingkat kesesuaian pembentukan kelembagaan petani dengan kebutuhan dan aspirasi anggota dan tingkat keterbukaan pengelolaan kelembagaan petani); akses terhadap tenaga ahli, kelembagaan penyuluhan dan penelitian (tingkat kemudahan petani menemui penyuluh, akses terhadap hasil-hasil penelitian); fasilitasi oleh 
Tabel 1. Hasil Penilaian (Skor) Karakteristik Sistem Sosial $\left(\mathrm{X}_{2}\right)$

\begin{tabular}{|llll|}
\hline Peubah Nilai Skor $(\mathrm{n}=180)$ & $\mathrm{X}_{21}$ & Nilai-nilai \\
Sosial Budaya $\mathrm{X}_{21}$ & & & \\
& Nilai Skor $(\mathrm{n}=180)$ & $\mathrm{X}_{21}$ & Nilai-nilai Sosial \\
Budaya $\mathrm{X}_{21}$ & & & \\
$\mathrm{X}_{21}$ Nilai-nilai Sosial Budaya $\mathrm{X}_{21}$ & 62,26 & $\mathrm{X}_{22}$ & Sis \\
Akses terhadap Tenaga Ahli, Kelembagaan & \\
\hline Peubah Nilai Skor $(\mathrm{n}=180)$ & $\mathrm{X}_{21}$ & Nilai-nilai Sosia \\
Budaya $\mathrm{X}_{21}$ & & & \\
Nilai Skor $(\mathrm{n}=180)$ & $\mathrm{X}_{21}$ & Nilai-nilai Sosial Budaya \\
$\mathrm{X}_{21}$ & & & \\
$\mathrm{X}_{21}$ Nilai-nilai Sosial Budaya $\mathrm{X}_{21}$ & 62,26 & $\mathrm{X}_{22}$ & Siste \\
Akses terhadap Tenaga Ahli, Kelembagaan & \\
\hline
\end{tabular}

lembaga pemerintah terkait agribisnis; akses terhadap kelembagaan agribisnis (tingkat kemudahan petani akses terhadap sarana produksi, teknologi spesifik lokasi, permodalan, pemasaran dan pengolahan hasil) dan dukungan pemimpin lokal terhadap kemajuan pertanian, termasuk kategori "cukup" (ke arah baik, namun belum baik).

\section{Tingkat Kinerja Penyuluhan}

\section{$\underline{\text { Pertanian dalam Memberdayakan Petani }}$}

Kinerja penyuluh pertanian dalam memberdayakan petani adalah perilaku aktual yang diperagakan penyuluh sebagai kewajibannya mengemban tugas-tugas pemberdayaan yang diamanahkan kepadanya, yang diukur dari tingkat kepuasan petani. Amanah dalam arti kesadaran penyuluh untuk mampu mempertanggungjawabkan pekerjaannya tidak hanya kepada manusia tetapi juga kepada Tuhan. Berdasarkan temuan penelitian, tingkat kinerja penyuluh pertanian dalam memberdayakan petani terdiri dari 6 aspek (Tabel 2) termasuk kategori "cukup." Artinya, kinerja pemberdayaan yang meliputi: pengembangan perilaku inovatif petani (kinerja penyuluh dalam meningkatkan pengetahuan, keterampilan, sikap dan adopsi inovasi); penguatan partisipasi petani (kinerja penyuluh membantu/memfasilitasi petani mengidentifikasi kebutuhannya, melibatkan petani dalam proses perencanaan, pelaksanaan dan evaluasi program penyuluhan);

penguatan kelembagaan petani (kinerja penyuluh memanfaatkan potensi kelembagaan petani yang berakar kuat dari dalam masyarakat, memotivasi/memfasilitasi kerjasama dan dinamika kelompok.); penguatan akses terhadap berbagai sumberdaya (kinerja penyuluh memotivasi/memfasilitasi petani menemukan/memanfaatkan inovasi, kemudahan mendapatkan/menyediakan sarana produksi yang berkualitas, modal usaha, teknologi pertanian spesifik lokasi, pemasaran yang menguntungkan dan akses tekhnologi pengolahan hasil pertanian); penguatan kemampuan petani berjaringan (kinerja penyuluh memotivasi dan memfasilitasi petani menjalin kerjasama dalam dan antar kelompok tani, serta dengan kelembagaan agribisnis lain) dan kaderisasi (kinerja penyuluh menumbuhkan kader-kader petani untuk pendampingan dan mendampingi kader jika menemui kesulitan) termasuk kategori "cukup" (sudah ke arah baik, namun belum relatif baik).

Berdasarkan pengamatan di lapangan, wawancara mendalam dan analisis dokumen resmi, beberapa kelemahan yang ditemui di lapangan berkaitan dengan kinerja penyuluh pertanian dalam memberdayakan petani, adalah sebagai berikut:

(1) Penyuluh sebagian besar tidak berdomisili di wilayah kerjanya. Hal ini jelas akan mengurangi efektifitas kinerja penyuluh. 
Tabel 2. Hasil Penilaian (Skor) Kinerja Penyuluh Pertanian dalam Memberdayakan Petani

\begin{tabular}{|l|c|}
\hline \multicolumn{1}{|c|}{ Sub Peubah } & Nilai Skor Rataan $(\mathrm{n}=300)$ \\
\hline $\begin{array}{l}\text { Kinerja Penyuluh Pertanian dalam } \\
\text { Memberdayakan Petani (Y }\end{array}$ & 58,22 \\
\hline $\mathrm{Y}_{11}$ Pengembangan Perilaku Inovatif & 58,78 \\
\hline $\mathrm{Y}_{12}$ Penguatan Partisipasi Petani & 58,22 \\
\hline $\mathrm{Y}_{13}$ Penguatan Kelembagaan Petani & 56,24 \\
\hline $\mathrm{Y}_{14}$ Penguatan Akses Petani terhadap Berbagai & 61,91 \\
\hline $\mathrm{Y}_{15}$ Sumberdaya & 57,25 \\
\hline $\mathrm{Y}_{16}$ Kaderisasi & 58,78 \\
\hline
\end{tabular}

Keterangan: Kategori penilaian: $0-\leq 40=$ sangat kurang baik; $40-\leq 55=$ kurang baik; $55-\leq 70=$ cukup , $70-\leq 85=$ baik dan $85-\leq 100=$ sangat baik

(2) Balai Informasi Penyuluhan (BIP) sebagai basis kegiatan penyuluh, lebih merupakan perpanjangan tangan Kantor Informasi Pertanian (KIP) di tingkat kabupaten. BIP tidak diberi dana otonom untuk penyelenggaraan kegiatan penyuluhan di wilayah kerjanya.

(3) Belum terselenggara koordinasi yang baik antara lembaga penyuluhan baik di tingkat desa, kecamatan maupun kabupaten dengan dinas-dinas terkait sehubungan dengan pemberdayaan petani. Masing-masing instansi masih bersifat egosektoral dan petani hanya sebagai objek dari sebuah kegiatan pembangunan.

(4) Latar belakang pendidikan, golongan kepangkatan dan jabatan fungsional penyuluh belum optimal mendukung kinerja penyuluh pertanian.

\section{Faktor-faktor yang Berpengaruh terhadap KinerjaPenyuluh Pertanian dalam Memberdayakan Petani}

Berdasarkan uji regresi berganda, faktor-faktor yang berpengaruh positif nyata (pada taraf 5 dan 10 persen) terhadap kinerja penyuluh pertanian dalam memberdayakan petani adalah: karakteristik petani (pendidikan non formal); karakteristik sistem sosial (nilainilai sosial budaya; akses petani terhadap lembaga agribisnis dan fasilitasi agribisnis oleh lembaga pemerintah terkait) dan kompetensi penyuluh pertanian (yaitu kompetensi penyuluh berkomunikasi; kompetensi penyuluh membelajarkan petani dan kompetensi penyuluh interaksi sosial). Persamaan regresi bergandanya adalah: $\mathrm{X}_{4}=$ $3,811+0,071 \mathrm{X}_{13} *+0,095 \mathrm{X}_{21} * *+$ $0,098 \mathrm{X}_{24}{ }^{* *}+0,141 \mathrm{X}_{25} * *+0,305 \mathrm{X}_{32} * *+$ $0,327 \mathrm{X}_{33} * *+0,301 \mathrm{X}_{34} * *$.

Hasil uji analisis berganda ini adalah untuk menguji hipotesis, yaitu: "Karakteristik petani, karakteristik sistem sosial dan kompetensi penyuluh pertanian berpengaruh secara nyata terhadap kinerja penyuluh pertanian dalam memberdayakan petani." Ternyata hipotesis tersebut terbukti diterima untuk faktor karakteristik petani (yaitu faktor pendidikan non formal); faktor karakteristik sistem sosial (yaitu nilai-nilai sosial budaya; akses terhadap lembaga agribisnis dan fasilitasi oleh lembaga pemerintah terkait agribisnis) dan faktor kompetensi penyuluh pertanian (yaitu kompetensi penyuluh berkomunikasi; kompetensi penyuluh membelajarkan petani dan kompetensi 


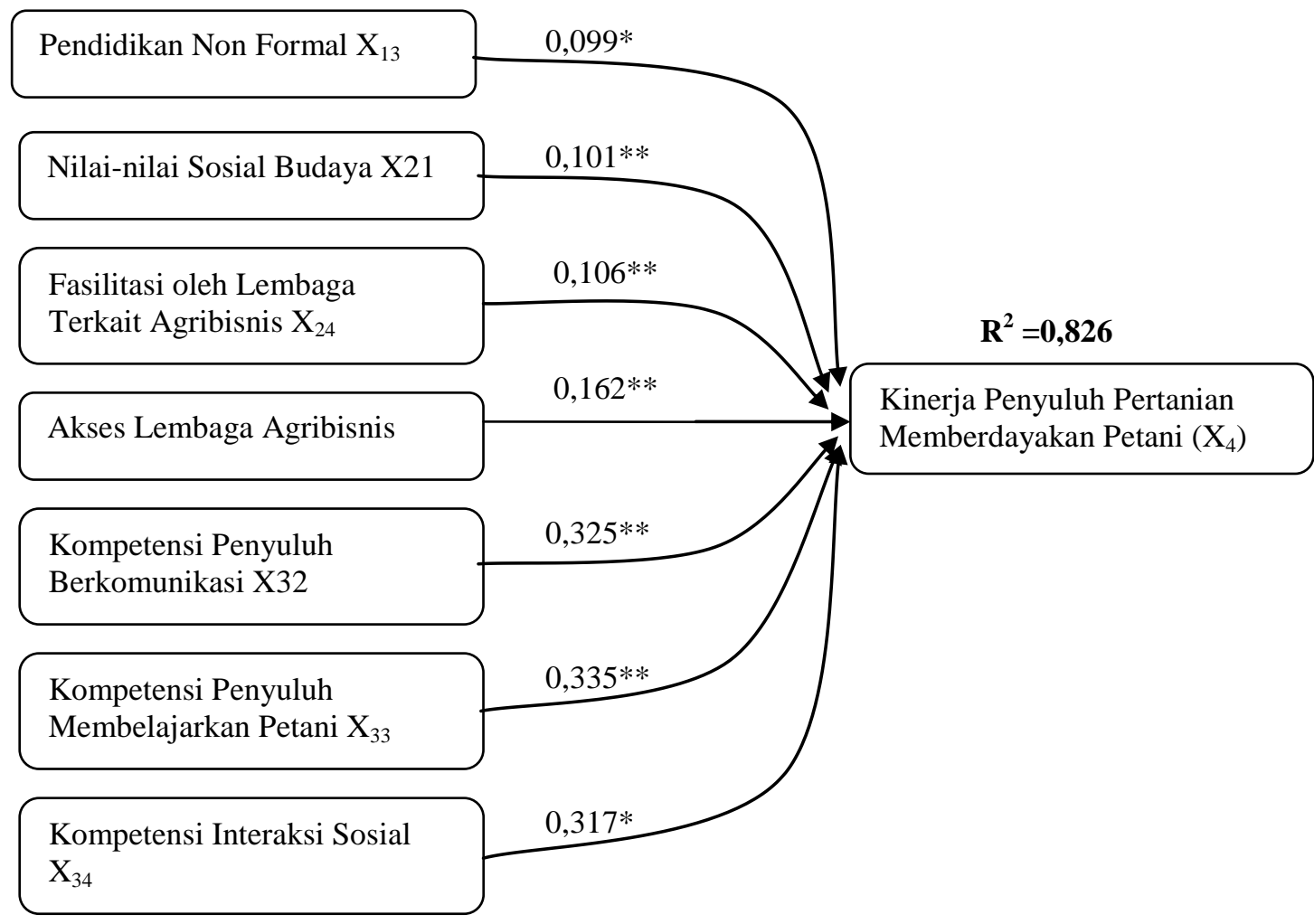

$$
\begin{aligned}
& \text { Keterangan: } \\
& \begin{array}{l}
* *=\text { nyata pada taraf } 5 \text { persen } \\
* \quad=\text { nyata pada taraf } 10 \text { persen }
\end{array}
\end{aligned}
$$

Gambar 1. Faktor-faktor yang Berpengaruh terhadap Kinerja Penyuluh Pertanian dalam Memberdayakan Petani

penyuluh berinteraksi sosial). Koefisien $\mathrm{R}$ kuadrat (koefisien determinasi) dari faktorfaktor ini adalah 0,826 atau 82,6 persen. Artinya, besarnya pengaruh langsung faktorfaktor tersebut secara bersama-sama terhadap kemandirian petani beragribisnis adalah sebesar 0,826 atau 82,6 persen. Adapun sisanya, yaitu 17,4 persen dijelaskan oleh faktor-faktor lain di luar model.

Faktor-faktor yang berpengaruh dan besarnya pengaruh secara sendiri-sendiri (parsial) terhadap kinerja penyuluh pertanian memberdayakan petani dilihat dari koefisien Beta (koefisien regresi yang sudah distandarkan), disajikan pada Gambar 1. Temuan penelitian ini memberikan implikasi bahwa kinerja penyuluh pertanian dapat diperbaiki dengan meningkatkan akses petani terhadap pendidikan non formal; dukungan sistem sosial (khususnya:nilai-nilai sosial budaya; fasilitasi oleh lembaga pemerintah terkait agribisnis dan dukungan kelembagaan agribisnis) dan meningkatkan kompetensi penyuluh (khususnya kompetensi penyuluh berkomunikasi; kompetensi penyuluh membelajarkan petani dan kompetensi penyuluh berinteraksi sosial.

Faktor-kaktor karakteristik petani (umur, pendidikan formal, pengalaman beragribisnis dan luas penguasaan lahan) tidak berpengaruh signifikan terhadap kinerja penyuluh. Artinya, karakteristik petani belum berperan terhadap kinerja penyuluh atau sebaliknya kinerja penyuluh belum memperhatikan (berdasarkan) karakteristik petani, kecuali pendidikan non formal. Dalam 
melakukan pemberdayaan seharusnya penyuluh juga memperhatikan karakteristik petani seperti usia, tingkat pendidikan formal dan pengalaman petani.

Faktor-faktor karakteristik sistem sosial yang lain yaitu: sistem kelembagaan petani; akses petani terhadap tenaga ahli, kelembagaan penelitian dan penyuluhan dan kepemimpinan lokal belum berpengaruh secara nyata terhadap kinerja pemberdayaan oleh penyuluh pertanian. Faktor-faktor ini seharusnya juga ditingkatkan untuk lebih meningkatkan tingkat kinerja penyuluh pertanian dalam memberdayakan petani.

Kompetensi manajerial penyuluh tidak berpengaruh nyata terhadap kinerja penyuluh pertanian dalam memberdayakan petani. Artinya, kompetensi kewirausahaan yang dimiliki oleh penyuluh pertanian belum mendukung kinerja penyuluh pertanian. Hal ini disebabkan oleh kompetensi wirausaha penyuluh pertanian belum relatif tinggi (kategori "cukup"). Manajemen yang dilakukan penyuluh adalah manajemen terpusat atau sudah terpola dari pusat. Penyuluh harus mengikuti manajemen yang sudah ditentukan oleh pihak atas dan terjebak oleh perencanaan, pelaksanaan dan evaluasi kegiatan penyuluhan yang seragam, terstruktur dan dipertanggungjawabkan sesuai dengan ketentuan pihak atas yang lebih berorientasi belum kepentingan petani. Di lain pihak, petani memiliki permasalahan dan kebutuhan yang berbeda-beda, yang seharusnya perencanaan, pelaksanaan dan evaluasi kegiatan penyuluhan pertanian berdasarkan analisis kebutuhan petani.

Strategi Peningkatan Kinerja Penyuluh $\underline{\text { Pertanian dalam Memberdayakan Petani }}$

Strategi peningkatan kinerja penyuluh pertanian dalam memberdayakan petani adalah:

(1) Meningkatkan faktor-faktor yang berpengaruh terhadap kinerja penyuluh pertanian dalam memberdayakan petani, yaitu dengan meningkatkan kompetensi penyuluh pertanian; dukungan positif sistem sosial dan akses petani terhadap pendidikan non formal. Kompetensi penyuluh yang strategis untuk ditingkatkan yaitu kompetensi: komunikasi (efektifitas berkomunikasi, kemampuan menjalin relasi, menggunakan media komunikasi, dll.); mengorganisasikan kegiatan belajar petani (kemampuan memotivasi, mengelola kegiatan belajar, kemampuan menggunakan berbagai metode belajar, dan lain-lain) dan interaksi sosial (kemampuan untuk diterima masyarakat, kemampuan mengatasi konflik, dll.). Karakteristik sistem sosial yang strategis untuk ditingkatkan adalah adalah: nilainilai sosial budaya; fasilitasi oleh lembaga pemerintah terkait agribisnis, akses terhadap kelembagaan agribisnis.

(2) Meningkatkan kinerja penyuluh pertanian dengan meningkatkan kualitas kerja yang berkaitan dengan tugas utama penyuluh pertanian dalam memberdayakan petani yaitu: (a) pengembangan perilaku inovatif; (b) penguatan partisipasi petani; (c) penguatan kelembagaan petani; (d) penguatan akses terhadap berbagai sumberdaya; (e) penguatan kemampuan petani berjaringan dan (f) kaderisasi. Hal ini disebabkan karena, kenyataanya aspek-aspek kinerja penyuluh pertanian dalam memberdayakan petani termasuk kategori "cukup" (relatif belum baik)).

\section{$\underline{\text { Kesimpulan }}$}

(1) Petani berada pada usia produktif dan pengalaman beragribisnis cukup lama, namun belum ditunjang oleh pendidikan formal dan non formal yang tinggi serta belum didukung oleh luas penguasaan lahan pertanian yang memadai.

(2) Tingkat kinerja penyuluh pertanian dalam memberdayakan petani relatif belum baik (kategori "cukup"), hal ini disebabkan oleh faktor-faktor yang berpengaruh nyata terhadap kinerja 
penyuluh pertanian yaitu: karakteristik sistem sosial (nilai-nilai sosial budaya; fasilitasi agribisnis oleh lembaga pemerintah dan akses petani terhadap kelembagaan agribisnis) dan kompetensi penyuluh (kompetensi komunikasi; kompetensi penyuluh membelajarkan petani dan kompetensi penyuluh berinteraksi sosial), termasuk kategori "cukup" dan kompetensi wirausaha penyuluh tidak berpengaruh nyata terhadap kinerja penyuluh dalam memberdayakan petani.

\section{$\underline{\text { Rujukan }}$}

Aninomous. 2006. Undang-undang Republik Indonesia Nomor 16 Tahun 2006 tentang Sistem Penyuluhan Pertanian, Perikanan dan Kehutanan. Diperoleh dari: http://www.deptan.go.id/bpsdm/penyulu han/index.htm; Internet; diakses tanggal 3/14/2008.

Ife, Jim. 1995. Community Development: Creating Community Alternatives-Vision, Analysis and Practice. Melbourne: Longman Australia, Pty Ltd.
Narayan, Deepa. 2002. Empowerment and Proverty Reduction: a Sourcebook. Washington, D.C: World Bank.

Sumardjo, Saharuddin, dan, Nuning, Kusumowardani. 2003. Pendampingan dalam Rangka Pemberdayaan Kelembagaan Lumbung Pangan. (Laporan Akhir). Bogor: Bagian Proyek Pengembangan Ketahanan Pangan Masyarakat Badan Bimas Ketahanan Pangan dan Pusat Studi Pemba-ngunan LP-IPB.

Slamet, Margono. 2003. Pemberdayaan Masyarakat. Dalam Membentuk Pola Perilaku Manusia Pembangunan. Penyunting: Ida Yustina dan Ajat Sudrajat, 45-48. Bogor: IPB Press.

Sajogyo. 1999. Memacu Perekonomian Rakyat. Jakarta: Aditya Media 